Lihui Luo (ORCID ID: 0000-0002-9471-7373)

Lixin Wang (ORCID ID: 0000-0003-0968-1247)

Wenzhi Zhao (ORCID ID: 0000-0003-1757-226X)

\title{
Increased human pressures on the alpine ecosystem along the Qinghai-Tibet Railway
}

Lihui Luo ${ }^{1,2^{*}}$, Quntao Duan ${ }^{1,2}$, Lixin Wang ${ }^{3}$, Wenzhi Zhao ${ }^{1,2}$, Yanli Zhuang ${ }^{1,2,3}$

${ }^{1}$ Linze Inland River Basin Research Station, Key Laboratory of Inland River Basin Ecohydrology, Northwest Institute of Eco-Environment and Resources, Chinese Academy of Sciences, Lanzhou 730000, China

${ }^{2}$ University of Chinese Academy of Sciences, Beijing 100049, China

${ }^{3}$ Department of Earth Sciences, Indiana University-Purdue University Indianapolis (IUPUI), Indiana 46202, USA

* Corresponding author: luolh@1zb.ac.cn

Lihui Luo_luolh@lzb.ac.cn

Quntao Duan duanqt@1zb.ac.cn

Lixin Wang 1xwang@iupui.edu

Wenzhi Zhao zhaowzh@1zb.ac.cn

Yanli Zhuang zhuangyl@lzb.ac.cn

This is the author's manuscript of the article published in final edited form as:

Luo, L., Duan, Q., Wang, L., Zhao, W., \& Zhuang, Y. (2020). Increased human pressures on the alpine ecosystem along the Qinghai-Tibet Railway. Regional Environmental Change, 20(1), 33. https://doi.org/10.1007/s10113-020-01616-7 


\section{Abstract}

Construction of the Qinghai-Tibet Railway (QTR) increased the links between inland China and the Qinghai-Tibet Plateau (QTP). The QTR accelerated surrounding tourism, boosted the local economy, and led to rapid development of livestock raising. To assess how distance from the railway and different regions have influenced the impact of the QTR on the alpine ecosystem, human footprint maps were produced to indicate human pressures, and the normalized difference vegetation index (NDVI), an index of vegetation greenness, was used to characterize the growth of alpine vegetation. The construction and operation of the QTR have increased human pressures, while the establishment of nature reserves has effectively reduced human pressures. The QTR contributes significantly to the increased human pressures in the Tibetan region compared with the Qinghai region and exerts negative impacts on alpine vegetation. Although the warmer and wetter climate trend has proven beneficial in enhancing alpine vegetation greenness, the declining trend of alpine vegetation has been stronger in regions with more intensive human pressures, especially in the grazing areas and the tourist areas around Lhasa. These results suggest that the impact of the QTR on alpine vegetation in Tibet is greater than that in Qinghai and that the spatial extent of the indirect impact of the QTR in Tibet is confined to approximately $30 \mathrm{~km}$ from the railway. These results will provide guidance and a theoretical basis for the protection of the alpine environment on the QTP under intensified anthropogenic influence.

Keywords: Alpine ecosystem; Qinghai-Tibet Railway; Human footprint; Vegetation greenness; Impact assessment 


\section{Length of the manuscript}

5638 words (4865 text words, and 497 words of tables and figures)

1 table and 7 figures 


\section{Introduction}

Alpine ecosystems, which account for only 3\% of the world's land area, are fragile and extremely sensitive to global climate change and human activities (Scholz et al. 2017). Natural and anthropogenic interferences are key to the development of alpine ecosystem spatiotemporal heterogeneity (Murthy and Bagchi 2018; Schroter 2005) and affect the composition and functioning of alpine ecosystems (Ma et al. 2017; Xu et al. 2018). Although recent climate change has primarily contributed to alpine environmental change, human activities also exert important impacts (Wang et al. 2014b). Over the past three centuries, the impact of humans on the global environment has escalated (Crutzen 2002).

The alpine ecosystem on the Qinghai-Tibet Plateau (QTP) has undergone universal and significant warming in recent decades, and the rate of warming is approximately twice the global average from 1960-2009 (Chen et al. 2013; Hansen et al. 2010). At the same time, precipitation has exhibited a slight increase in large parts of the QTP. Temperature and moisture are considered the two key factors driving the formation and development of alpine vegetation. Previous studies have shown that human activities also cause major disturbances to alpine ecosystems (Chen et al. 2014; Li et al. 2018b). Due to the combined effects of climate change and human activities, multiple studies have demonstrated that alpine vegetation on the QTP has improved, but some areas have become degraded (Chen et al. 2014; Huang et al. 2016; Ma et al. 2017; Pan et al. 2017). Increasing human activities, such as increases in human population, land cover and land use change, grazing pressure, and engineering construction, have profoundly 
intensified the threats to alpine ecosystems (Huang et al. 2016; Li et al. 2016).

The central area of the QTP is its most populated area and is a critical engineering and transportation corridor that connects inland China and the QTP (Luo et al. 2018a). This area is called the Qinghai-Tibet Engineering Corridor (QTEC), with a total length of more than $1120 \mathrm{~km}, 632 \mathrm{~km}$ of which is permafrost. The corridor is a unique and vulnerable high-altitude ecosystem (Luo et al. 2018c) and represents an ideal area to study the impact of human activities on alpine ecosystems, especially the impact of the construction and operation of the Qinghai-Tibet Railway (QTR), which began in 2001 and 2006, respectively. The QTR is considered a landmark project, as it was the first time in history that railway transport from Golmud in Qinghai Province to Lhasa of the Tibet Autonomous Region had been introduced. The QTR has alleviated traffic bottlenecks that hinder the economic and social development of the QTP. The QTR accelerated surrounding tourism markedly due to the increased accessibility and affordability of travel to Tibet (Su and Wall 2009).

The alpine ecosystem in the QTEC is extremely sensitive to climate change and human disturbance (Luo et al. 2018b). It is therefore critical to determine how the alpine ecosystem of the QTEC responds to the joint influences of climate and human activities. Related research in this area has mainly focused on alpine vegetation responses to climate change, while human activities, especially the influence of the QTR, have seldom been addressed (Luo et al. 2018b). To obtain more insights into the ecological effects of the QTR on the alpine ecosystem in the QTEC, the QTR was used as a trigger factor to investigate long-term vegetation responses to climate and human 
activities in the QTEC. In terms of scope and extent of impact, previous work has tended to ignore the effects of distance between alpine vegetation and the QTR.

The normalized difference vegetation index (NDVI) and net primary productivity (NPP) are two effective indicators of vegetation growth condition. Many studies employing direct and indirect methods to characterize the intensity and extent of human activities (Li et al. 2018b; Venter et al. 2016b) or to quantify the part of the ecosystem that is affected exclusively by human activities (DeFries et al. 1999; Niedertscheider et al. 2012; Wessels et al. 2004) have been carried out. Indirect methods for evaluating the regional impact of human activities on ecosystems include the NDVI residual trend method (Wang et al. 2012; Wessels et al. 2004) and the model-based human appropriation of NPP (HANPP) method (DeFries et al. 1999). Neither method directly represents the intensity and extent of human activities. The NDVI residual trend method can provide meaningful results only if there is a strong linear relationship between the NDVI and precipitation (Burrell et al. 2017). Current HANPP models rarely include harvest or land use feedback with ecosystems, which can lead to estimation errors (Pan et al. 2016). The human footprint is a method used to directly represent the intensity and extent of human activities through direct and indirect human pressures (Venter et al. 2016a). A map of human pressures on the land surface is called a "human footprint". The human footprint represents the sum of ecological footprints of the human population, and its changes reveal the impact of humans on nature (Sanderson et al. 2002).

In this study, our objective was to determine the impacts of human activities on 
the alpine ecosystem along the QTR. Specifically, this study aimed to (1) map the human footprints in 2001 and 2015 in the QTEC and reveal their spatial and temporal characteristics; (2) analyse spatiotemporal variation in alpine vegetation from 2001 to 2015; and (3) assess the impacts of changes in the human footprint along the QTR on changes in alpine vegetation.

\section{Materials and Methods}

\subsection{Study area}

The QTEC is centred on the QTR with a maximum extent of $120 \mathrm{~km}$ and an average elevation of approximately 4700 metres; approximately $80 \%$ of the extent has an elevation greater than 4000 metres (Fig. 1a). Alpine grasslands are the main vegetation type on the QTP and provide essential ecosystem services to people living in the area. Alpine grasslands account for approximately $62 \%$ of the QTEC, and bare soil accounts for approximately $29 \%$ (Fig. 1b). The annual mean precipitation in the corridor is between 250 and $600 \mathrm{~mm}$. Most of the corridor is located in a semi-arid region, which is characterized by the Indian monsoon in summer and by westerlies in winter. Most alpine vegetation in this region greens up in late May and turns yellow at the end of September. The study area contains eight nature reserves, including Hoh Xil (Kekexili), the Three-River Headwaters (Sanjiangyuan), Chang Tang, Lin-chou Pengbo, and La-lu. One of these reserves is an internationally important Ramsar site, and the Hoh Xil (Kekexili) and Three-River Headwaters (Sanjiangyuan) national nature reserves are the two largest nature reserves on the QTP, primarily located in

Qinghai Province. The Hoh Xil and Three-River Headwaters national nature reserves 
were established in 1997 and 2000, respectively. Nature reserves account for approximately $38 \%$ of the corridor area and are mainly distributed in Qinghai Province (Fig. 1a). Golmud, Amdo, Nagchu, Damxung and Lhasa are the five cities located in the corridor and the five stations of the QTR, with Golmud and Lhasa being the two largest cities, home to populations of more than 100000 people (Fig. 1c). The Tibetan area of the QTEC is dominated by grazing, including the three main pastoral areas of Amdo, Nagchu and Damxung, while most of the Qinghai area consists of nature reserves.

\subsection{Data}

\subsubsection{Meteorological forcing}

Weather station data from the area surrounding the QTEC were obtained from the China Meteorological Administration (CMA, http://data.cma.cn). These data were merged with Global Land Data Assimilation System (GLDAS, https://las.gsfc.nasa.gov) data through time conversion, height correction, spatial interpolation, offset correction and data postprocessing to produce a new gridded data set from 2001 to 2015 with a daily $0.1^{\circ}$ temporal-spatial resolution. The gridded meteorological forcing data set included precipitation and air temperature.

\subsubsection{Satellite-based NDVI}

To characterize the growth of alpine vegetation, the NDVI was used to describe vegetation greenness. The Advanced Very High Resolution Radiometer (AVHRR) developed by the National Oceanic and Atmospheric Administration (NOAA) was used 
generate the third-generation Global Inventory Modeling and Mapping Studies (GIMMS 3g) NDVI data set. Moderate Resolution Imaging Spectroradiometer (MODIS) was designed specifically for vegetation monitoring. GIMMS $3 \mathrm{~g}$ data with 8-km and 15-day spatial and temporal resolutions, respectively ((http://glcf.umd.edu/data/gimms/), and MODIS data (MOD13A2) with 500-m and 16day spatial and temporal resolutions, respectively, for the period from 2001-2015 were obtained (https://lpdaac.usgs.gov/getdata/datapool) as NDVI data sets. Four MODIS tiles - h24v05, h24v06, h25v05, and h25v06 - were acquired to cover our study region.

\subsubsection{Human footprint}

A human footprint map is a quantitative measurement of human pressures on Earth's land surface. Data on human pressures, including land use/cover, night time light, population density, grazing density, and road and railway distributions, were collected to generate human footprint maps of the QTEC for 2001 and 2015 at a 1-km resolution. These data were weighted and aggregated based on estimates of relative human stress levels to create a standardized human footprint and were assigned a pressure score from $0-10$ for each grid, where 0 means unpressured and 10 means maximum pressure. The scores of these types of human pressure were summed to determine the value of the human footprint. Table 1 provides scores based on Venter et al. (2016a). The construction and operation of the QTR and the establishment of nature reserves were considered important factors strongly linked to changes in human activities, and the scores were changed accordingly.

Land use/cover data for the QTEC were extracted for 2001 from GLC2000 
(Bartholomé and Belward 2005) and for 2015 from Land Cover 2015 with a 1-km spatial resolution (http://chinageoss.org/geoarc/2017/B/sjxz.html).

Night time light emissions indicate human activity patterns, and DMSP-OLS version 4 data were used to represent night time light (Elvidge et al. 2001). Night time light data for 2015 were unavailable, so we used 2013 data instead.

The population density data used were from the 1-km-grid Chinese population density data set obtained from the Resource and Environment Data Cloud Platform of the Chinese Academy of Sciences (http://www.resdc.cn/DOI/doi.aspx?DOIid=32); the data for 2001 were replaced with data for 2000. A maximum population density of 36850 people $\mathrm{km}^{-2}$ was assigned a score of 10 , and the scores were logarithmically scaled as follows:

$$
\text { Score }=2.19 \times \log (\text { population density }+1)
$$

Grazing density data were derived from the Gridded Livestock of the World 2 (GLW2) database, and data for the Chinese region were derived from 2001 Chinese agricultural data (Baylis et al. 2014). The 2015 grazing data were based on the ratio of livestock slaughter numbers in the 2000 and 2015 yearbooks of the counties in the two provinces.

Road and railway density data were acquired from the Global Roads Open Access Data Set gROADS v1 for 2001 (CIESIN 2013). Data for the QTR were added to the 2015 data. More details are provided in Table 1.

\subsubsection{Statistical data}

Data on the total number of visitors, output of meat and milk, and pasture area and 
protected pastoral area in the QTEC were collected from Qinghai and Tibet statistical yearbooks for 2001 to 2015 . Land use change data were procured from the National Bureau of Statistics of China (http://data.stats.gov.cn). The two data sets are based on county- and municipal-level statistical data, respectively. The number of wild animals was obtained from the White Paper of the State Council Information Office of the People's Republic of China, which was released on July 18, 2018 (http://www.scio.gov.cn/zfbps/32832/Document/1633978/1633978.htm).

\subsection{Data analyses}

Noise filtering of NDVI data from mixed forest and croplands in the growing season improves their utility (He et al. 2017). In our study area, the type of vegetation is mainly alpine grassland, for which the effect of noise filtering is minimal. Before assessing the impact of human pressures on the NDVI, the spatial resolution of MODIS NDVI trend data was reduced to $1 \mathrm{~km}$ using the nearest resampling approach. To analyse the relationships between the NDVI trend and human footprint change, linear regression analyses and Pearson correlation coefficients were applied. In addition, the ggplot2 R package was used to draw correlation graphs. Locally estimated scatterplot smoothing (LOESS) regression was conducted for total precipitation, air temperature, human footprint change and NDVI trend to reveal irregular change trends.

To detect the rates of change in growing season vegetation greenness, trend analysis was used to calculate the long-term trend of change in the NDVI for the QTEC from 2001 to 2015 (Luo et al. 2018b), using the following equation: 


$$
\text { Trend }=\frac{n \times \sum_{i=1}^{n}\left(i \times \operatorname{NDVI}_{i}\right)-\left(\sum_{i=1}^{n} i\right) \times\left(\sum_{i=1}^{n} N D V I_{i}\right)}{n * \sum_{i=1}^{n} i^{2}-\left(\sum_{i=1}^{n} i\right)^{2}},
$$

where NDVI $\mathrm{i}_{\mathrm{i}}$ is the NDVI in year $\mathrm{i}$ and $\mathrm{n}$ is 15 , representing the total number of years from 2001 to 2015. A positive value from trend analysis of the NDVI would suggest an increase in vegetation greenness, while a negative value would indicate a decrease in vegetation greenness; zero would show that vegetation greenness has not changed.

To evaluate the statistical significance of monotonic temporal trends, the MannKendall trend test was used to identify NDVI trends and to estimate the abrupt change in total precipitation and air temperature. The spatial distribution of the statistical significance of NDVI trends was mapped and assessed based on two-tailed significance tests of the Mann-Kendall trend test results.

To assess the spatial extent of railway influence, we established multiple buffers for the railway. Specifically, the buffers of the QTR were defined for 15 intervals between 1 and $120 \mathrm{~km}$ within the engineering corridor (i.e., 1, 2, 5, 10, 20, 30, 40, 50, $60,70,80,90,100,110$ and $120 \mathrm{~km})$. Spatial metrics were calculated to examine the impact of the QTR on the alpine ecosystem through buffer analysis of the QTR. The impacts of the railway on the alpine ecosystem of Qinghai and Tibet were then compared to evaluate the difference in QTR influence between the two regions.

All statistical analyses were performed using the $\mathrm{R}$ statistical program ( $\mathrm{R}$ Development Core Team 2017). In particular, the Mann-Kendall trend test and spatial data operations were performed using the raster, rgdal, kendall and pheno R packages. 


\section{Results}

\subsection{Regional climatic changes}

Total precipitation falls mainly during the growing season (from May to September) on the QTP, with winters and springs being relatively dry compared to other periods. Precipitation showed a nonsignificant trend in Qinghai and Tibet $(\mathrm{P}>0.05)$. However, total precipitation in the growing season in the Qinghai and Tibetan regions of the QTEC showed an overall increase of 13 and $6 \mathrm{~mm}$, respectively, per decade from 2001-2015 (Fig. 2a). The air temperature has increased by 0.36 and $0.50{ }^{\circ} \mathrm{C}$ per decade in the Qinghai and Tibet regions of the QTEC, respectively, since 2001 (Fig. 2b). The increase in growing season precipitation in Qinghai was greater than that in Tibet, while the growing season air temperature in Tibet exhibited a larger increase than that in Qinghai. The temperature trend in the QTEC showed ubiquitous and rapid warming, with a significant increase $(\mathrm{P}<0.001)$. These results show that the corridor has become warmer and wetter in recent decades. There was no statistically significant trend shift for atmospheric forcing based on the Mann-Kendall trend test.

\subsection{Human pressure changes}

From 2001 to 2015 , the mean values of human pressure increased by $40 \%$ in the QTEC (Fig. 3a-c). The human pressure for 2001-2015 in the Qinghai and Tibetan regions of the QTEC increased by 1.03 and 1.74, respectively, and the increase rates were 29 and $57 \%$, respectively. The human pressures in the southeastern regions of Lhasa, Amdo, Damxung and Nagchu have increased substantially. In addition, 29\% and 
$1 \%$ of the study area in Qinghai and Tibet, respectively, experienced decreases. A more pronounced decline occurred in the Hoh Xil and Three-River Headwaters national nature reserves. Although human pressures in nature reserves showed a large downward trend, there were sporadic increasing trends in the eastern region of Qinghai. The use of zonal statistics in 1-km to $120-\mathrm{km}$ buffer zones to assess the contribution of the QTR to human pressures revealed that the human pressure changes in every buffer zone were greater in Tibet than in Qinghai. Furthermore, the changes between the two regions tended to stabilize for buffer zones greater than $30 \mathrm{~km}$. These results suggest that the closer the QTR is, the greater the human pressures will be within a 30-km buffer zone, especially in the Tibetan region of the corridor (Fig. 3d).

\subsection{Trends in alpine vegetation greenness}

By analysing the spatial change trend of GIMMS NDVI data, we found that $40 \%$ of the areas had decreased in vegetation greenness, 16\% of which appeared in Qinghai and $67 \%$ of which appeared in Tibet (Fig. 4a). MODIS NDVI data showed that $22 \%$ of areas have decreased in vegetation greenness, including 7\% in Qinghai and 39\% in Tibet (Fig. 4b). The significant declines $(\mathrm{P}<0.1)$ in GIMMS NDVI and MODIS NDVI accounted for 33\% and 7\% of significant changes, respectively. For Qinghai and Tibet, the significant declining trend of GIMMS NDVI accounted for $9 \%$ and $75 \%$ of the total area, and MODIS NDVI decreased by $2 \%$ and $25 \%$, respectively (Fig. $4 \mathrm{c}-\mathrm{d}$ ). The areas with a significantly increasing NDVI were much larger than the areas with decreasing trends. The two NDVI data sets showed that the vegetation degradation in Tibet was much greater than that in Qinghai. 
NDVI decreasing trends were mainly concentrated around the 5 cities of the QTEC. The spatial distributions of deteriorated and improved areas were similar for MODIS NDVI and GIMMS NDVI, so the growing season MODIS NDVI trend was selected to detect the areas with decreasing trends for different land use/cover data in the QTEC. Furthermore, a decreasing trend of MODIS NDVI was mostly observed in croplands, followed by shrublands, forests, grasslands and wetlands (Fig. S1). However, without grasslands, the remaining four vegetation types (croplands, shrublands, forests and wetlands) accounted for only approximately $5 \%$ of the corridor area, which indicates that the area of NDVI decline in grasslands was the largest among all vegetation types (Fig. S1). On the QTP, alpine grassland is used for wildlife (?)grazing or uncontrolled livestock grazing. Most of the NDVI trends in the nature reserves were increasing, with $80 \%$ and $91 \%$ increases in the trends of GIMMS NDVI and MODIS NDVI, respectively. The increasing trend of NDVI in nature reserves was much higher than the overall increasing trend of NDVI in the QTEC.

The buffer analysis indicated that the NDVI change trends in the two NDVI data sets were generally similar but different in terms of the range in different buffer zones. There were larger gaps in the NDVI trends of Tibet than in those of Qinghai, suggesting more dramatic vegetation degeneration in Tibet than in Qinghai. The trend of the NDVI in Qinghai was generally stable, and there were decreasing trends for the NDVI in the $30-\mathrm{km}$ railway buffer zone. However, the NDVI trends in Tibet increased gradually with increasing distance from the QTR, and at distances greater than $30 \mathrm{~km}$, the trends of change in MODIS NDVI tended to be stable. The MODIS 
NDVI trends in the $20-\mathrm{km}$ buffer zone were less than 0 in Tibet, whereas all the GIMMS

NDVI trends within 120-km buffers were less than 0 . The spatial resolutions of the two NDVI data sets were different, but the spatial patterns of NDVI trends in Qinghai and Tibet were similar (Fig. 5).

\subsection{Human pressures on alpine vegetation greenness}

The spatial relationship between the trend of growing season MODIS NDVI and the change in human pressures from 1-km to 120-km buffer zones in Qinghai (Fig. 6) and Tibet (Fig. 7) was investigated. The two regions exhibited different spatial patterns of correlations. Human pressures had a significant negative correlation with vegetation growth in Tibet $(\mathrm{P}<0.001)$, while Qinghai showed a significant positive correlation ( $\mathrm{P}$ $<0.001$ ) with a very weak correlation coefficient. In the corridor, although there were a few spots with reduced human pressure, the trend of most MODIS NDVI data increased where human pressures decreased. Nature reserves were the main areas with human pressure reductions. The correlation coefficients in different buffer zones in the Qinghai region were similar, but the correlation coefficients were much smaller than those in Tibet.

The QTR contributed significantly to the increase in human pressure up to a distance of approximately $30 \mathrm{~km}$, especially in the Tibetan region of the QTEC, and the MODIS NDVI trend in Tibet within $30 \mathrm{~km}$ of the railway decreased. The human pressures and decline in NDVI were more significantly correlated within $30 \mathrm{~km}$ of the railway than at other distances. Human pressures caused by the railway resulted in a decline in the NDVI within a $30-\mathrm{km}$ buffer and showed that the impact of such a large 
area of declining vegetation greenness was not direct. The transportation constraints mean that human activities within the QTEC are concentrated in the grazing areas and the tourist areas around Lhasa, which are therefore subject to more human pressure. Human pressure in the Tibetan region has a greater impact than that in the Qinghai region on alpine vegetation and leads to a decrease in alpine vegetation greenness, in terms of both area and the NDVI. Vegetation changes in the Tibetan region of the corridor appear to be driven by the effect of increasing human pressures. However, human pressures in the Qinghai region have decreased due to the establishment of a larger area of nature reserves, and the alpine vegetation greenness in the area has increased. These results suggest that the impact of the QTR on NDVI changes along the QTR was more dramatic in Tibet than in Qinghai, and the extent of the impact of human pressures was approximately $30 \mathrm{~km}$.

\section{Discussion}

In the study area, the climate is getting wetter and warmer. There have been many studies on the effects of climate change on alpine vegetation on the QTP, and the consensus is that increases in precipitation improve alpine vegetation vitality (Cuo et al. 2016; Fu et al. 2018; Wang et al. 2014a; Zuo et al. 2010). Furthermore, the increase in air temperature has advanced green-up dates, delayed the withering period, and lengthened the growing season of alpine vegetation (Cong et al. 2017; Ding et al. 2012; Zhang et al. 2013). Previous studies revealed similar results and showed that a warmer and slightly wetter climate positively influences alpine vegetation growth in the QTEC

(Chen et al. 2014; Luo et al. 2018b). However, very few studies have investigated the 
direct and indirect impacts of the QTR on the local alpine ecosystem (Wang et al. 2015).

\subsection{Positive effects of human activities on the alpine ecosystem}

During the periods of railway construction and its operation, various protective measures were taken, including restoring vegetation around the railway, designing specific routes for people and vehicles, and using a dry drilling method to avoid pollution of soil and vegetation by drilling mud (Peng et al. 2007). Some ecological projects have been implemented on the plateau, and positive results have been achieved in the protection of ecosystems, which have controlled the degradation of local ecosystems and restored biodiversity (Zhang et al. 2018). Among these projects, the grassland restoration project was launched in 2002 (Chen et al. 2014). As of 2012, 5.76 million hectares of pasture was returned to protected pastoral areas. From 2004-2012, the sizes of the protected pastoral areas of Amdo, Nagqu and Damxung were $0.59,0.30$ and 0.28 million hectares, respectively. The nature reserves in the QTEC are home to nearly 500 wild animal species, including Tibetan antelopes, wild yaks, wild Tibetan donkeys, and snow leopards, many of which are endangered (Leclerc et al. 2015). In the case of the Tibetan antelope, the population is estimated to have declined by more than $50 \%$ from $1980-1999$. When poaching was at its peak in the $1990 \mathrm{~s}$, the number had fallen below 20000, but the population had already reached more than 60000 in 2015. Meanwhile, the populations of wild yaks and Tibetan donkeys increased by $50 \%$ from 2000-2015. The restoration and expansion of rare and endangered species in the QTEC provide evidence of the positive impact of biodiversity conservation (Cumming et al. 2015). 


\subsection{Negative effects of human activities on the alpine ecosystem}

Since 2001, an economic boom in this region has rapidly increased the population within the QTEC, especially around Lhasa (Luo et al. 2018b). Due to its unique natural environment and cultural characteristics, Lhasa has long been a tourist destination for people in China and other regions (Su and Wall 2009). Interestingly, the increase in visitors surpassed that in residents. Since 2006, tourism has been developing rapidly and has become a pillar industry in Tibet. Lhasa and its surroundings have become the most visited area of the QTP. The tourism industry expanded rapidly, and the large influx of visitors provided a boost to the local economy (Guo 2016). However, economic development generated a strong demand for livestock and led to the rapid development of livestock raising. Animal husbandry accounts for $25 \%$ of Tibet's gross domestic product (GDP). The main industry of Amdo, Nagqu and Damxung is animal husbandry. The nomadic lifestyle in this area is disappearing quickly. Instead, the modern urban lifestyle is now much more common among Tibetans in China. The output of meat (milk) from four counties in the Tibetan portion of the corridor increased by $180 \%$ (139\%) from 15 (18) million $\mathrm{kg}$ in 2001 to 42 (43) million $\mathrm{kg}$ in 2015 . The alpine ecosystem has therefore evolved as a consequence of frequent disturbances, especially in the Tibetan region of the corridor, where intensive human activities have resulted in the overexploitation of grassland resources (Huang et al. 2016). This condition has led to more threats to livestock farming and pasture management, increasing their vulnerability, increasing the deterioration of pasture lands, and severely affecting alpine grassland ecosystems. The human pressure in Tibet is much greater 
than that in Qinghai, suggesting that Tibet may face more threats induced by human activities. Alpine vegetation greenness in Tibet responded strongly to the human pressure. At present, the main problem associated with the grassland restoration project is that the subsidy for the project in Tibet is less than 5000 yuan per capita per year, which is lower than the annual grazing income of herdsmen and thus affects the enthusiasm of herdsmen to participate in the project (Yeh 2005). Moreover, 6.97 million hectares of grassland has been fenced since 2008. During this process, pastures have been fenced, and grazing areas have been reduced. Although the warmer and wetter climatic trend observed over the course of this study has proven beneficial for enhancing alpine vegetation greenness, the declining trend of alpine vegetation greenness has tended to be stronger in regions with stronger human pressures. The results of this study suggest that enhanced human pressures along the QTR may have had a negative impact on alpine vegetation, especially in the grazing areas and the tourist areas around Lhasa in the Tibetan region, while the establishment of nature reserves has had the opposite effect (Li et al. 2018a).

\section{Conclusions}

In addition to the impact of climate change, human activities are also a key factor impacting alpine ecosystems in a human-dominated world, with alpine vegetation greenness varying with human pressure. We combined satellite-derived vegetation greenness, meteorological forcing data and human footprint maps to evaluate the effects of human activities on the alpine ecosystem along the QTR. The establishment of nature reserves in the QTEC has been effective in reducing human pressures, while the 
construction of the QTR contributed significantly to increases in human pressures. Tibet endured more human pressures in the corridor than did Qinghai from 2001-2015, which threatened the alpine ecosystem in Tibet. NDVI trends showed that the decline in the NDVI in the Tibetan region, especially in the grazing areas and the tourist areas around Lhasa, was much greater than that in the Qinghai region. Our results demonstrate that the construction and operation of the QTR have accelerated surrounding tourism, boosted the local economy, and decreased surrounding alpine vegetation greenness in an indirect way. Furthermore, the spatial extent of the QTR's indirect impact on alpine vegetation in Tibet has been limited to approximately $30 \mathrm{~km}$ from the railway. In areas where human pressures have decreased, the alpine environment has been restored. Understanding the response of the alpine environment to climate change and human activities is essential for minimizing the impact of human activities in the QTEC. These results can provide guidance and a theoretical basis for the protection of the alpine ecosystem on the QTP under intensified human activities.

\section{Acknowledgements}

This research was jointly supported by the National Natural Science Foundation of China (41871065), the National Key R\&D Program of China (2018YFB1502800), and the Key Research Project of Frontier Science of Chinese Academy of Sciences (QYZDJ-SSW-DQC040). We are grateful to the editors and anonymous reviewers for their constructive and helpful comments, which greatly strengthened this manuscript.

\section{References}


Bartholomé E, Belward AS (2005) GLC2000: a new approach to global land cover mapping from Earth observation data. Int J Remote Sens 26(9):1959-1977. https://doi.org/10.1080/01431160412331291297

Baylis M, Robinson TP, Wint GRW, Conchedda G, Van Boeckel TP, Ercoli V, Palamara E, Cinardi G, D'Aietti L, Hay SI, Gilbert M (2014) Mapping the Global Distribution of Livestock. PLoS ONE 9(5):e96084. https://doi.org/10.1371/journal.pone.0096084

Burrell AL, Evans JP, Liu Y (2017) Detecting dryland degradation using Time Series Segmentation and Residual Trend analysis (TSS-RESTREND). Remote Sens Environ 197:43-57. https://doi.org/10.1016/j.rse.2017.05.018

Chen B, Zhang X, Tao J, Wu J, Wang J, Shi P, Zhang Y, Yu C (2014) The impact of climate change and anthropogenic activities on alpine grassland over the Qinghai-Tibet Plateau. Agricultural and Forest Meteorology 189:11-18. https://doi.org/10.1016/j.agrformet.2014.01.002

Chen H, Zhu QA, Peng CH, Wu N, Wang YF, Fang XQ, Gao YH, Zhu D, Yang G, Tian JQ, Kang XM, Piao SL, Ouyang H, Xiang WH, Luo ZB, Jiang H, Song XZ, Zhang Y, Yu GR, Zhao XQ, Gong P, Yao TD, Wu JH (2013) The impacts of climate change and human activities on biogeochemical cycles on the Qinghai-Tibetan Plateau. Global Change Biol 19(10):2940-2955. https://doi.org/10.1111/gcb.12277

CIESIN (2013) Global Roads Open Access Data Set, Version 1 (gROADSv1). NASA Socioeconomic Data and Applications Center (SEDAC), Palisades, NY. https://doi.org/10.7927/H4VD6WCT

Cong N, Shen M, Piao S, Chen X, An S, Yang W, Fu YH, Meng F, Wang T (2017) Little change in heat requirement for vegetation green-up on the Tibetan Plateau over the warming period of 1998-2012. Agricultural and Forest Meteorology 232:650-658. https://doi.org/10.1016/j.agrformet.2016.10.021

Crutzen PJ (2002) Geology of mankind. Nature 415(6867):23-23. https://doi.org/10.1038/415023a

Cumming GS, Allen CR, Ban NC, Biggs D, Biggs HC, Cumming DHM, De Vos A, Epstein G, Etienne M, Maciejewski K, Mathevet R, Moore C, Nenadovic M, Schoon M (2015) Understanding protected area resilience: a multi-scale, social-ecological approach. Ecological Applications 25(2):299-319. https://doi.org/10.1890/13-2113.1

Cuo L, Zhang Y, Piao S, Gao Y (2016) Simulated annual changes in plant functional types and their responses to climate change on the northern Tibetan Plateau. Biogeosciences 13(12):3533-3548. https://doi.org/10.5194/bg-13-3533-2016

DeFries RS, Field CB, Fung I, Collatz GJ, Bounoua L (1999) Combining satellite data and biogeochemical models to estimate global effects of human-induced land cover change on carbon emissions and primary productivity. Global Biogeochemical Cycles 13(3):803-815. https://doi.org/10.1029/1999gb900037

Ding M, Zhang Y, Sun X, Liu L, Wang Z, Bai W (2012) Spatiotemporal variation in alpine grassland phenology in the Qinghai-Tibetan Plateau from 1999 to 2009. Chinese Sci Bull 58(3):396-405. https://doi.org/10.1007/s11434-012-5407-5

Elvidge CD, Imhoff ML, Baugh KE, Hobson VR, Nelson I, Safran J, Dietz JB, Tuttle BT (2001) Nighttime lights of the world: 1994-1995. Isprs J Photogramm 56(2):81-99. https://doi.org/10.1016/s0924-2716(01)00040-5

Fu G, Shen Z-X, Zhang X-Z (2018) Increased precipitation has stronger effects on plant production of an alpine meadow than does experimental warming in the Northern Tibetan Plateau. Agricultural and Forest Meteorology 249:11-21. https://doi.org/10.1016/j.agrformet.2017.11.017

Guo R (2016) China's Regional Development and Tibet. Springer, Singapore. 
https://doi.org/10.1007/978-981-287-958-5

Hansen J, Ruedy R, Sato M, Lo K (2010) Global Surface Temperature Change. Rev Geophys 48:RG4004. https://doi.org/10.1029/2010rg000345

He Y, Lee E, Warner TA (2017) A time series of annual land use and land cover maps of China from 1982 to 2013 generated using AVHRR GIMMS NDVI3g data. Remote Sens Environ 199:201-217. https://doi.org/10.1016/j.rse.2017.07.010

Huang K, Zhang YJ, Zhu JT, Liu YJ, Zu JX, Zhang J (2016) The Influences of Climate Change and Human Activities on Vegetation Dynamics in the Qinghai-Tibet Plateau. Remote Sens-Basel 8(10):876. https://doi.org/10.3390/rs8100876

Leclerc C, Bellard C, Luque GM, Courchamp F (2015) Overcoming extinction: understanding processes of recovery of the Tibetan antelope. Ecosphere 6(9):1-14. https://doi.org/10.1890/Es15-00049.1

Li J, Chen W, Liu Z (2018a) Geological Line Selection for the Qinghai-Tibet Railway Engineering. Springer, Berlin. https://doi.org/10.1007/978-3-662-55572-9

Li S, Wang Z, Zhang Y, Wang Y, Liu F (2016) Comparison of Socioeconomic Factors between Surrounding and Non-Surrounding Areas of the Qinghai-Tibet Railway before and after Its Construction. Sustainability-Basel 8(8):776. https://doi.org/10.3390/su8080776

Li S, Zhang Y, Wang Z, Li L (2018b) Mapping human influence intensity in the Tibetan Plateau for conservation of ecological service functions. Ecosystem Services 30:276-286. https://doi.org/10.1016/j.ecoser.2017.10.003

Luo L, Ma W, Zhao W, Zhuang Y, Zhang Z, Zhang M, Ma D, Zhou Q (2018a) UAV-based spatiotemporal thermal patterns of permafrost slopes along the Qinghai-Tibet Engineering Corridor. Landslides 15(11):2161-2172. https://doi.org/10.1007/s10346-018-1028-7

Luo L, Ma W, Zhuang Y, Zhang Y, Yi S, Xu J, Long Y, Ma D, Zhang Z (2018b) The impacts of climate change and human activities on alpine vegetation and permafrost in the Qinghai-Tibet Engineering Corridor. Ecol Indic 93:24-35. https://doi.org/10.1016/j.ecolind.2018.04.067

Luo L, Zhang Z, Ma W, Yi S, Zhuang Y (2018c) PIC v1.3: comprehensive R package for computing permafrost indices with daily weather observations and atmospheric forcing over the Qinghai-Tibet Plateau. Geosci Model Dev 11(6):2475-2491. https://doi.org/10.5194/gmd-11-2475-2018

Ma Z, Liu H, Mi Z, Zhang Z, Wang Y, Xu W, Jiang L, He J-S (2017) Climate warming reduces the temporal stability of plant community biomass production. Nat Commun 8:15378. https://doi.org/10.1038/ncomms 15378

Murthy K, Bagchi S (2018) Spatial patterns of long-term vegetation greening and browning are consistent across multiple scales: Implications for monitoring land degradation. Land Degrad Dev 29(8):24852495. https://doi.org/10.1002/ldr.3019

Niedertscheider M, Gingrich S, Erb K-H (2012) Changes in land use in South Africa between 1961 and 2006: an integrated socio-ecological analysis based on the human appropriation of net primary production framework. Regional Environmental Change 12(4):715-727. https://doi.org/10.1007/s10113-012-0285-6

Pan T, Zou X, Liu Y, Wu S, He G (2017) Contributions of climatic and non-climatic drivers to grassland variations on the Tibetan Plateau. Ecol Eng 108:307-317. https://doi.org/10.1016/j.ecoleng.2017.07.039

Pan Y, Yu C, Zhang X, Chen B, Wu J, Tu Y, Miao Y, Luo L (2016) A modified framework for the regional assessment of climate and human impacts on net primary productivity. Ecol Indic 60:184-191. https://doi.org/10.1016/j.ecolind.2015.06.017 
Peng CH, Ouyang H, Gao Q, Jiang Y, Zhang F, Li J, Yu Q (2007) Environment - Building a "green" railway in China. Science 316(5824):546-547. https://doi.org/10.1126/science.1134134

R Development Core Team (2017) R: A language and environment for statistical computing. R Foundation for Statistical Computing, Vienna, Austria

Sanderson EW, Jaiteh M, Levy MA, Redford KH, Wannebo AV, Woolmer G (2002) The Human Footprint and the Last of the Wild. BioScience 52(10):891. https://doi.org/10.1641/00063568(2002)052[0891:Thfatl]2.0.Co;2

Scholz K, Hammerle A, Hiltbrunner E, Wohlfahrt G (2017) Analyzing the Effects of Growing Season Length on the Net Ecosystem Production of an Alpine Grassland Using Model-Data Fusion. Ecosystems 21(5):982-999. https://doi.org/10.1007/s10021-017-0201-5

Schroter D (2005) Ecosystem Service Supply and Vulnerability to Global Change in Europe. Science 310(5752):1333-1337. https://doi.org/10.1126/science.1115233

Su MM, Wall G (2009) The Qinghai-Tibet railway and Tibetan tourism: Travelers' perspectives. Tourism Management 30(5):650-657. https://doi.org/10.1016/j.tourman.2008.02.024

Venter O, Sanderson EW, Magrach A, Allan JR, Beher J, Jones KR, Possingham HP, Laurance WF, Wood P, Fekete BM, Levy MA, Watson JEM (2016a) Global terrestrial Human Footprint maps for 1993 and 2009. Scientific Data 3(1):160067. https://doi.org/10.1038/sdata.2016.67

Venter O, Sanderson EW, Magrach A, Allan JR, Beher J, Jones KR, Possingham HP, Laurance WF, Wood P, Fekete BM, Levy MA, Watson JEM (2016b) Sixteen years of change in the global terrestrial human footprint and implications for biodiversity conservation. Nat Commun 7:12558. https://doi.org/10.1038/ncomms12558

Wang C, Guo H, Zhang L, Liu S, Qiu Y, Sun Z (2014a) Assessing phenological change and climatic control of alpine grasslands in the Tibetan Plateau with MODIS time series. International Journal of Biometeorology 59(1):11-23. https://doi.org/10.1007/s00484-014-0817-5

Wang G, Gillespie AR, Liang S, Mushkin A, Wu Q (2015) Effect of the Qinghai-Tibet Railway on vegetation abundance. Int $J$ Remote Sens 36(19-20):5222-5238. https://doi.org/10.1080/01431161.2015.1041179

Wang L, D'Odorico P, Evans JP, Eldridge DJ, McCabe MF, Caylor KK, King EG (2012) Dryland ecohydrology and climate change: critical issues and technical advances. Hydrology and Earth System Sciences 16(8):2585-2603. https://doi.org/10.5194/hess-16-2585-2012

Wang X, Ma W, Lang L, Hua T (2014b) Controls on desertification during the early twenty-first century in the Water Tower region of China. Regional Environmental Change 15(4):735-746. https://doi.org/10.1007/s10113-014-0661-5

Wessels KJ, Prince SD, Frost PE, van Zyl D (2004) Assessing the effects of human-induced land degradation in the former homelands of northern South Africa with a $1 \mathrm{~km}$ AVHRR NDVI timeseries. Remote Sens Environ 91(1):47-67. https://doi.org/10.1016/j.rse.2004.02.005

Xu W, Zhu M, Zhang Z, Ma Z, Liu H, Chen L, Cao G, Zhao X, Schmid B, He J-S, Toit Jd (2018) Experimentally simulating warmer and wetter climate additively improves rangeland quality on the Tibetan Plateau. Journal of Applied Ecology 55(3):1486-1497. https://doi.org/10.1111/1365$\underline{2664.13066}$

Yeh ET (2005) Green Governmentality and Pastoralism in Western China: 'Converting Pastures to Grasslands'. Nomadic Peoples 9(1):9-30. https://doi.org/10.3167/082279405781826164

Zhang G, Zhang Y, Dong J, Xiao X (2013) Green-up dates in the Tibetan Plateau have continuously advanced from 1982 to 2011. Proceedings of the National Academy of Sciences 110(11):4309-4314. 
https://doi.org/10.1073/pnas.1210423110

Zhang H, Fan J, Cao W, Zhong H, Harris W, Gong G, Zhang Y (2018) Changes in multiple ecosystem services between 2000 and 2013 and their driving factors in the Grazing Withdrawal Program, China. Ecol Eng 116:67-79. https://doi.org/10.1016/j.ecoleng.2018.02.028

Zuo Z, Zhang R, Zhao P (2010) The relation of vegetation over the Tibetan Plateau to rainfall in China during the boreal summer. Clim Dynam 36(5-6):1207-1219. https://doi.org/10.1007/s00382-0100863-6 
Table 1 Pressure scores were assigned to the six individual pressures in the human footprint maps.

\begin{tabular}{|c|c|c|}
\hline Data set & Pressure score & Details \\
\hline \multirow[t]{4}{*}{ Land use/cover } & $10,7,4,0$ & Built-up lands were assigned 10; croplands \\
\hline & & were assigned 7; grasslands were assigned \\
\hline & & 4 ; the other land use/cover types were \\
\hline & & assigned 0 \\
\hline Nighttime light & $0-10$ & Equal decile approach from 0 to 63 \\
\hline Population density & $0-10$ & $2.19 \times \log ($ population density +1$)$ \\
\hline Grazing density & $0-10$ & Equal decile approach from 0 to 5000 \\
\hline \multirow[t]{3}{*}{ Road distribution } & $0 \& 8$ for direct impacts & $0-500 \mathrm{~m}$ was assigned $8 ; 500 \mathrm{~m}-15 \mathrm{~km}$ was \\
\hline & $0-4$ for indirect impacts & assigned 4-1 using equal quartiles; $>15$ \\
\hline & & $\mathrm{km}$ was assigned 0 \\
\hline \multirow[t]{2}{*}{ Railway distribution } & 0,8 & $0-500 \mathrm{~m}$ was assigned $8 ;>500 \mathrm{~m}$ was \\
\hline & & assigned 0 \\
\hline
\end{tabular}



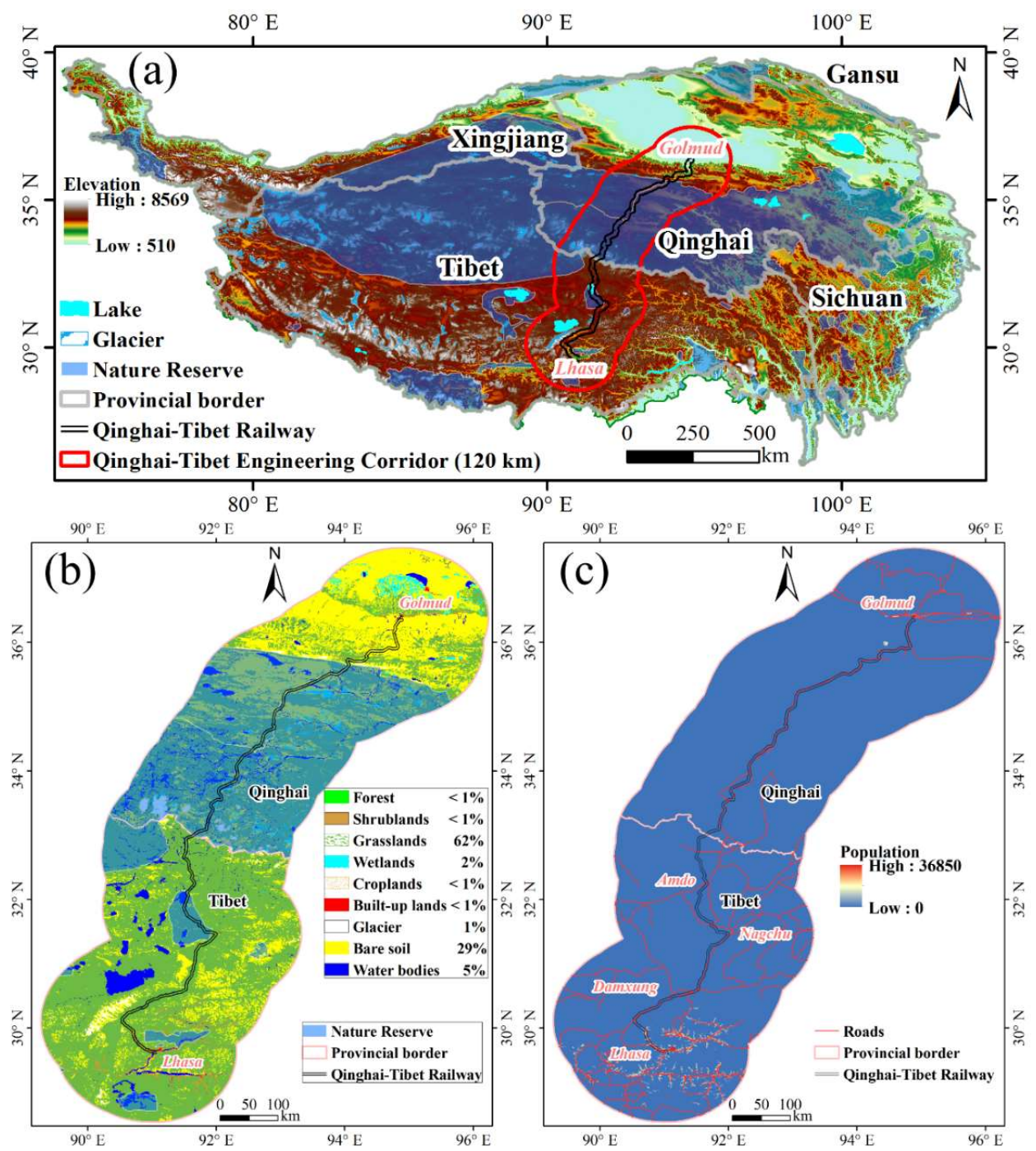

Fig. 1 Maps showing the location of the study area. (a) The Qinghai-Tibet Plateau (QTP) and Qinghai-Tibet Engineering Corridor (QTEC). The red border is the 1200$\mathrm{km}$ buffer zone of the railway. (b) Distribution of vegetation types and national nature reserves within the QTEC. (c) Distribution of populations and roads within the QTEC. 


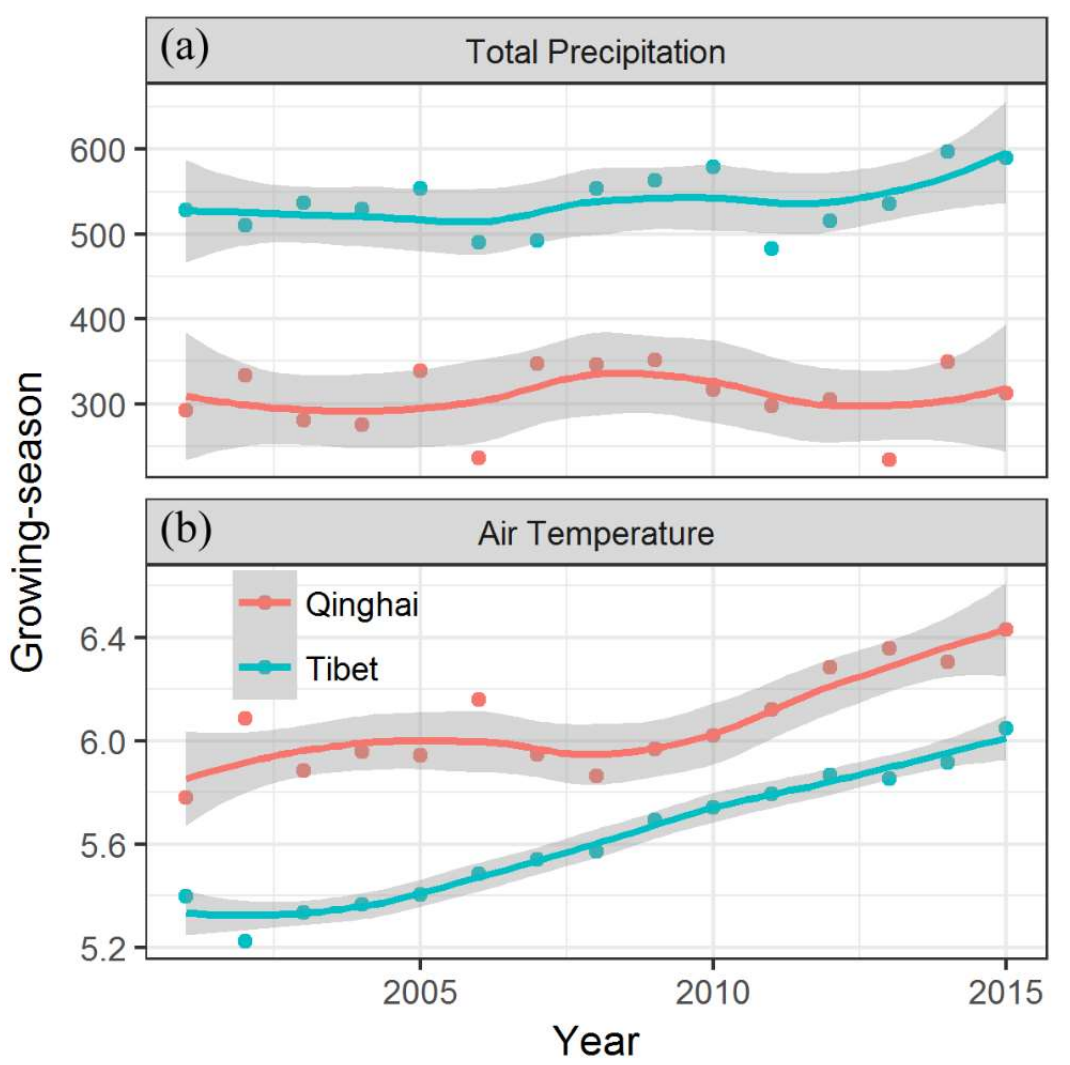

Fig. 2 Growing season meteorological factors for the 120-km buffer zone in the Qinghai and Tibet regions of the Qinghai-Tibet Engineering Corridor (QTEC) from 2001-2015. (a) Total precipitation $(\mathrm{mm})$; (b) mean air temperature $\left({ }^{\circ} \mathrm{C}\right)$. The grey-shaded area depicts $95 \%$ confidence intervals. 

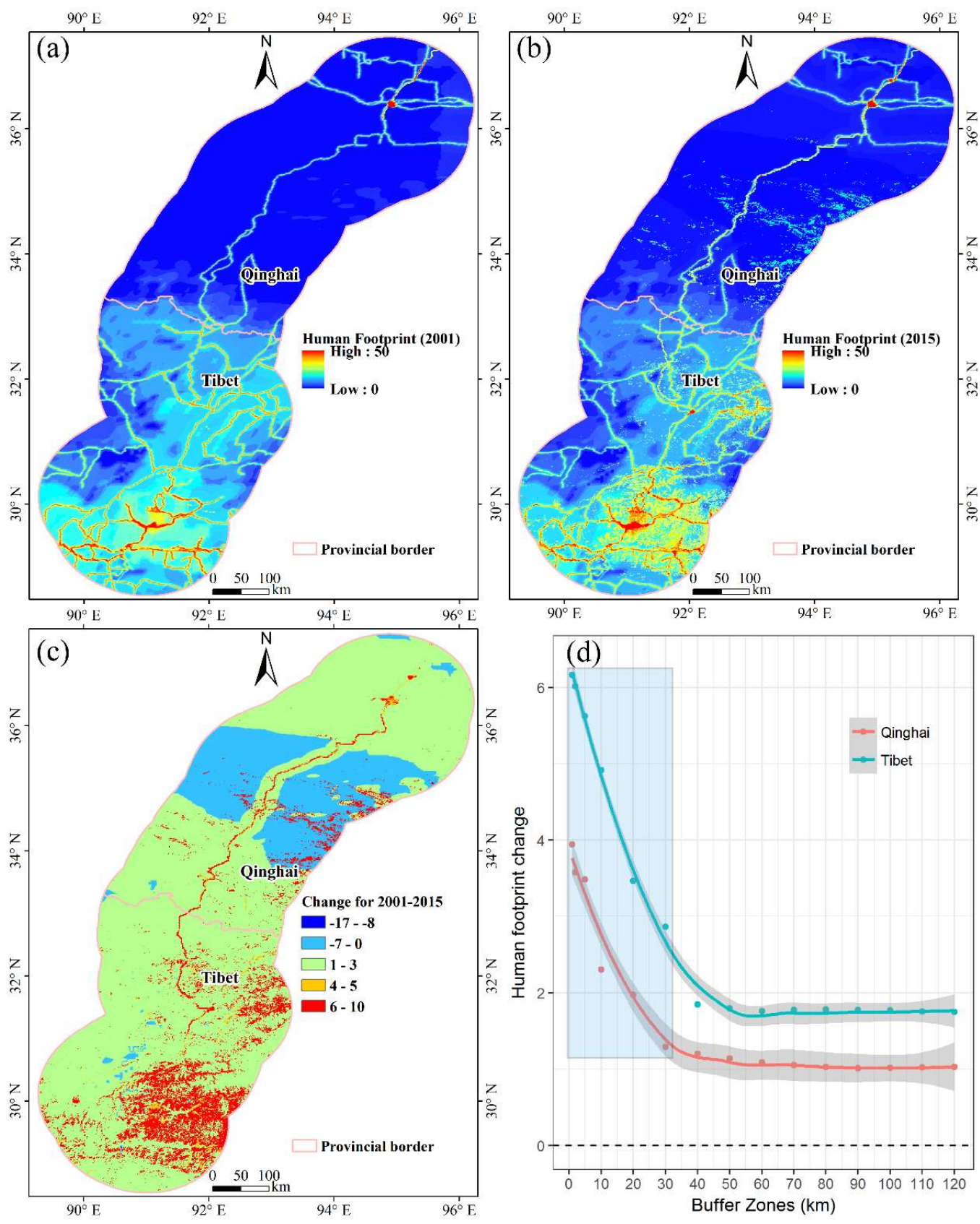

Fig. 3 Change in the human footprint in the Qinghai-Tibet Engineering Corridor (QTEC). (a) Human footprint map for 2001; (b) human footprint map for 2015; (c) change in human pressure for 2001-2015; (d) change in human pressure in different buffer zones for 2001-2015. The blue box represents the most dramatic areas of human pressure. The grey-shaded area depicts $95 \%$ confidence intervals. 

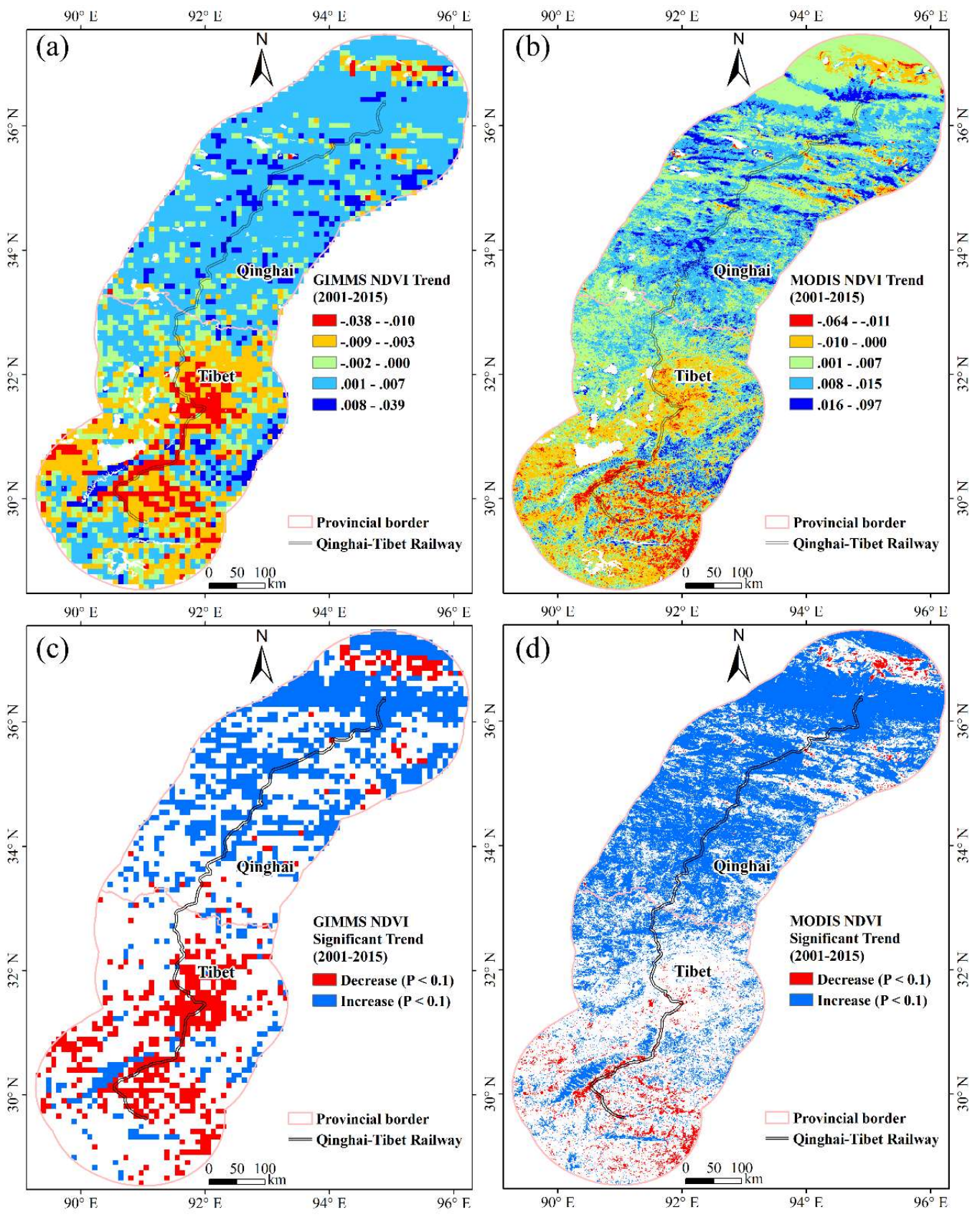

Fig. 4 Growing season normalized difference vegetation index (NDVI) change trends and significance levels from 2001-2015. (a) GIMMS NDVI change trend obtained with the linear regression method; (b) MODIS NDVI change trend obtained with the linear regression method; (c) significant trends for GIMMS NDVI obtained with MannKendall methods; (d) significant trends for MODIS NDVI obtained with the Mann- 
Kendall method. The blank regions of (c) and (d) indicate a P value $>0.1$.

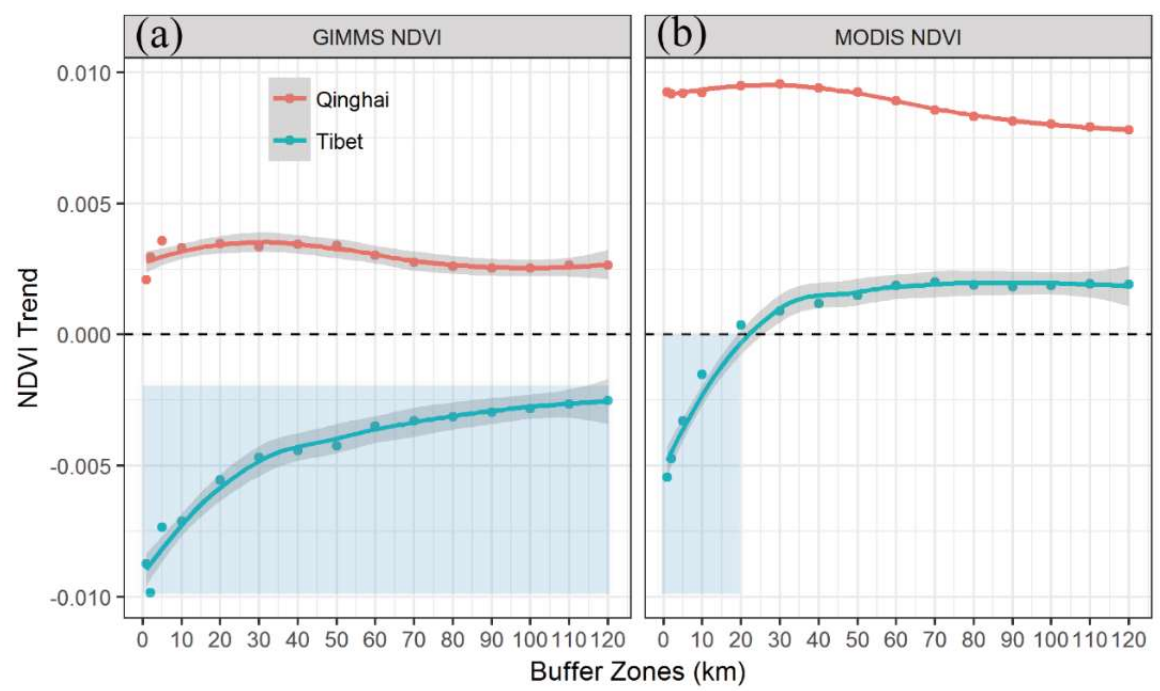

Fig. 5 Growing season normalized difference vegetation index (NDVI) change trends in different buffer zones from 2001-2015. (a) GIMMS NDVI trends in different buffer zones; (b) MODIS NDVI trends in different buffer zones. The blue boxes represent the most dramatic areas of NDVI trends. The grey-shaded area depicts $95 \%$ confidence intervals. 


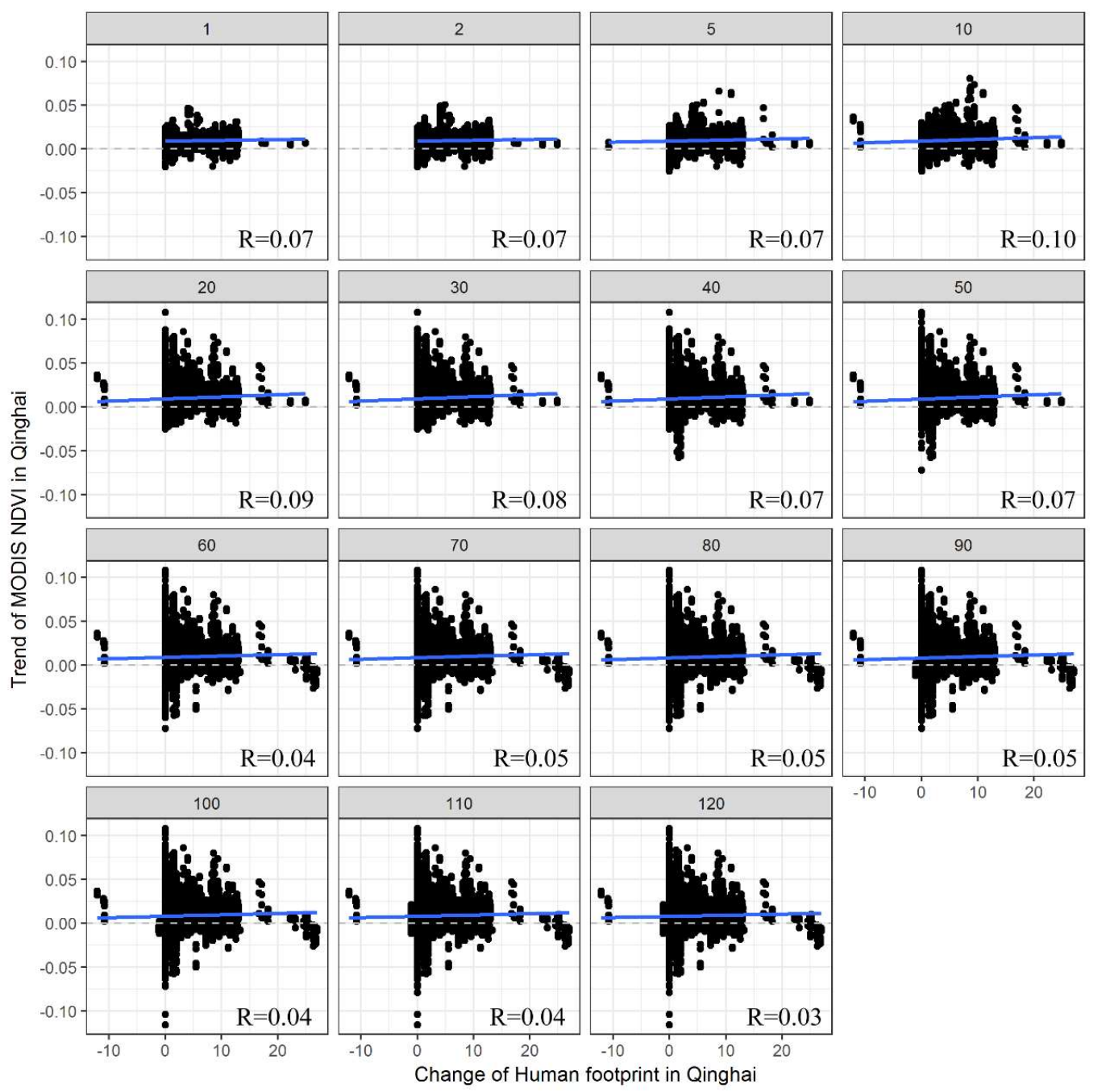

Fig. 6 Spatial relationship between the growing season MODIS normalized difference vegetation index (NDVI) trend and changes in the human footprint for $1-\mathrm{km}$ to $120-\mathrm{km}$ buffer zones in Qinghai. The number at the top of each figure represents the distance of the buffer zone. The blue lines show the fit from linear regression. 


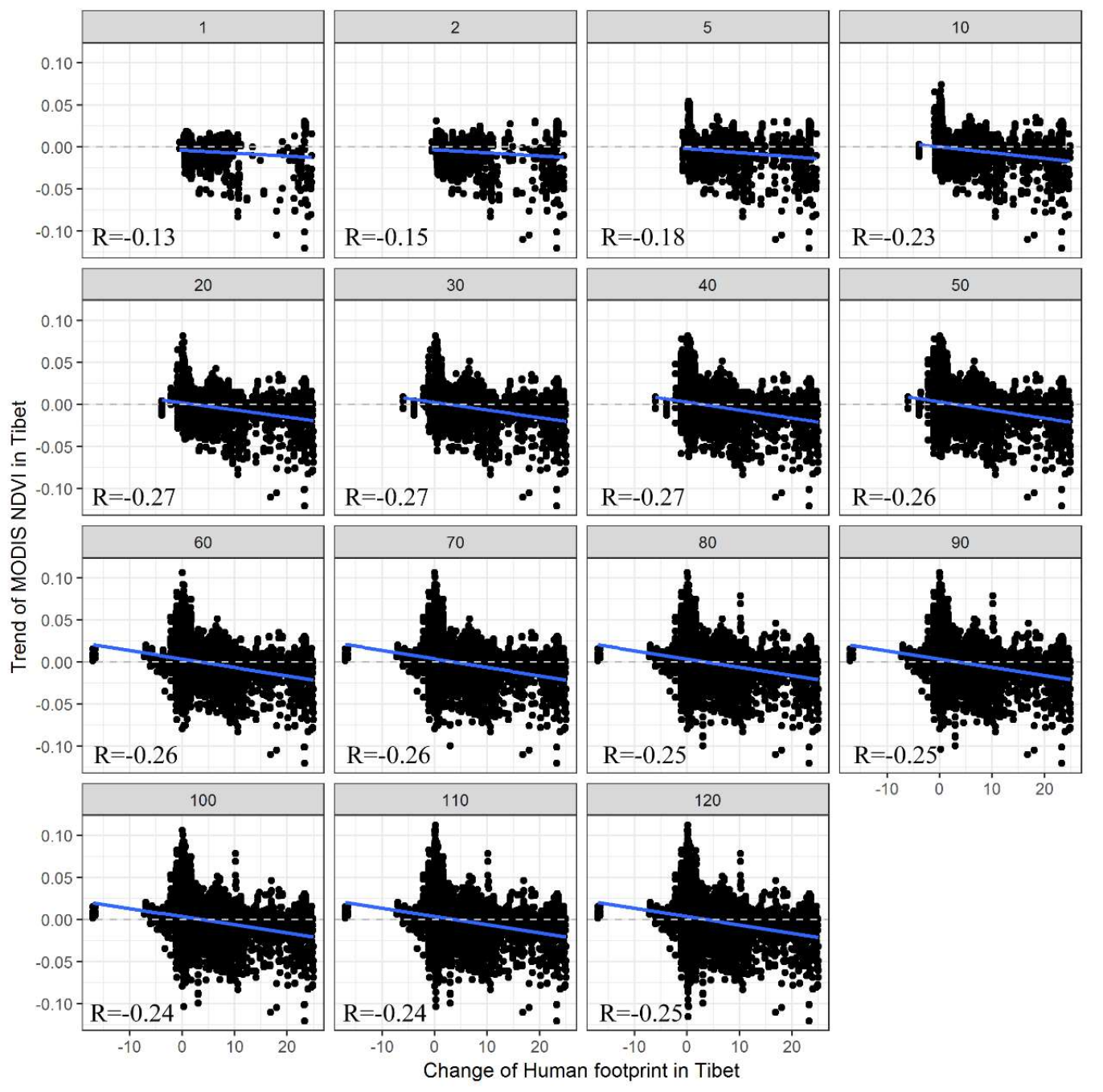

Fig. 7 Spatial relationship between the growing season MODIS normalized difference vegetation index (NDVI) trend and changes in the human footprint for $1-\mathrm{km}$ to $120-\mathrm{km}$ buffer zones in Tibet. The number at the top of each figure represents the distance of the buffer zone. The blue lines show the fit from linear regression. 